Sharif University of Technology
Scientia Iranica
Transactions E: Industrial Engineering
hCIttp://scientiairanica.sharif.edu
IRAN I CA

\title{
Pricing and advertising decisions in a dominant-retailer supply chain: A multi-follower bi-level programming approach
}

\author{
M. Mokhlesian and S.H. Zegordi* \\ Faculty of Industrial \& Systems Engineering, Tarbiat Modares University, Tehran, Iran. \\ Received 1 January 2016; received in revised form 26 November 2016; accepted 14 October 2017
}

\author{
KEYWORDS \\ Bi-level programming; \\ Pricing; \\ Dominant-retailer \\ supply chain; \\ Substitutable and \\ perishable products; \\ Cooperative \\ advertising; \\ Simulated annealing.
}

\begin{abstract}
Pricing and advertising is one of the most important decisions in each supply chain, especially in the competitive environment. In previous studies, this has been a centralized decision. However, if each channel member makes decision independently, the utility of all members is optimized. In such decentralized situations, channel members may have different market power to influence other members' decisions. These issues can be modeled through leader-follower Stackelberg game or bi-level programming. This study investigates coordination of pricing and cooperative advertising in a two-stage supply chain consisting of one dominant retailer and multiple competitive manufactures, producing several perishable and substitutable products. This paper aims to determine pricing and cooperative advertising decisions expenditure as well as the amount of manufacturers' production or retailer's purchase, such that the utility of all members is met. Hence, the problem is modeled as a multi-follower bi-level programming problem. Since it is proved that the model is NP-hard, the proposed model is solved through simulated annealing. A numerical example is used to show the impact of demand's variations on the members' decisions.
\end{abstract}

(C) 2018 Sharif University of Technology. All rights reserved.

\section{Introduction}

A supply chain consists of some members with possible different power structures. This study explores the members' decisions, whereas a retailer plays a more dominant role than manufacturers do (e.g., Wal-Mart and Tesco). 'Dominant' here implies a channel member with a power to control or influence another member's decisions [1]. Such large-scale retailers have significant influence on their suppliers so that they may have effect on the specifications of products. Wal-Mart is

\footnotetext{
*. Corresponding author. Tel.: +982182883394;

Fax: +982182883394

E-mail address: zegordi@modares.ac.ir (S.H. Zegordi)
}

the world's most important institution that controls the economy, privately. It has both positive and negative impacts on consumers based on its business style and performance. Some of these effects include a decrease in local prices, continual pressure on inflation, and continual cost investigation in a wide range of businesses that survive on lower profit margins [2].

In our channel, manufacturers engage in a horizontal competition; hence, pricing and advertising decisions as marketing tools become important. Often, these decisions are made collectively, simultaneously, which have an impact on the sales and on the profits of the supply chain members. While many researches were done on the advertising strategies or pricing policies in the past, few models considered both pricing and advertising decisions together because of the complexity of such models [3].

doi: $10.24200 /$ sci.2017.4535 
In this study, a two-stage supply chain with one dominant retailer and multiple competitive manufacturers is considered which produces a number of perishable and substitutable products. The channel members aim to determine values of their decision variables so that the utility of each member can be maximized. The utility of the retailer is its revenue and that of the manufacturers is their profit. The decision variables are the amount of production/purchase, advertising expenditure, and wholesale/retail prices as well as inventory level of the retailer. The chain has a decentralized structure in which each member has different powers to make decisions. To depict such situations, bi-level programming can be helpful.

The paper is organized as follows: First, in Section 2, we present a brief literature review. The next section describes the model as a multi-divisional bi-level programming model. Section 4 details the proposed algorithm, parameter tuning as well as performance measurement. In Section 5, managerial insights of this study are presented through a numerical example. Finally, this study is concluded by some recommendations for future study.

\section{Literature review}

Some researches in the literature investigated the supply chains with the dominant members. The concept of "retailer dominance" is studied in light of two aspects in the game-theoretic supply chain literature. The first aspect, "parallel dominance", considers a powerful retailer encroaching domination over other competing retailers (e.g., see $[4,5]$ ). The second aspect is "vertical dominance", where a retailer dominates a manufacturer in a Stackelberg gaming relationship (e.g., see $[6,7]$ that considered a dominant retailer dictating the unit wholesale price as well as the order quantity and unit retail price).

Hua and $\mathrm{Li}$ [1] developed retailer-dominant noncooperative game models in which the retailer's order quantity was sensitive to the manufacturer's wholesale price. Lau et al. [8] studied how a dominant retailer could design purchase contract in a newsvendortype product from a manufacturer with price-sensitive demand. Pan et al. [9] constructed a two-period model to discuss pricing and ordering problems for a dominant retailer with demand uncertainty in a declining price environment. Wang et al. [10] considered a dominated manufacturer supplying a dominant retailer with asymmetric cost information to design the purchase contract. Chen and Zhuang [11] considered coordination model in a supply chain with a dominant retailer's sales promotion opportunity and possible demand disruption. Wang et al. [12] investigated percentage-markup and dollar-markup pricing schemes for a Stackelberg-dominant retailer. They showed that if a dominant retailer shifted from dollar to percentage markup, the channel's "overall pie" and the retailer's "pie-piece" would be both enlarged. Dukes et al. [13] studied the product quality motivations in a channel with two asymmetric retailers and one common manufacturer. They demonstrated that if the lowservice retailer becomes dominant in the channel, it might lead to low-level quality that is damaging to the other members of the channel.

Several researches have been conducted on the coordination of pricing and advertising decisions in the supply chains. Yue et al. [14] and Szmerekovsky and Zhang [15] developed a price discount model to coordinate the advertising expenditures of the two parties in a two-echelon supply chain. They assumed that the consumer demand was dependent on the retail price and co-op advertising expenditure. Xie and Neyret [16] considered different classical types of relationships between a manufacturer and a retailer to identify the optimal pricing and co-op advertising strategies. Xie and Wei [17] studied the co-op advertising and pricing problems in a one-manufacturer one-retailer channel where the sales response is a function of advertising expenditures and retail price. Yan [18] studied both cooperative advertising and pricing strategy in a manufacturer-e-retailer supply chain for categories of products. The leader-follower Stackelberg and strategic alliance model was established. Aust and Buscher [19] applied the game theory to the existing research that deals with advertising and pricing decisions in a manufacturerretailer supply chain simultaneously. Zhang et al. [20] proposed a dynamic cooperative advertising model for a manufacturer-retailer supply chain and analyzed how the reference price effect would influence the decisions of all the channel members. Mokhlesian and Zegordi [21] considered coordination of pricing and inventory decisions in a two-echelon supply chain consisting of several competitive retailers and one manufacturing, who produces some substitutable products. Chintapalli [22] combined pricing and inventory control for the perishable goods, when demand is uncertain and price-sensitive.

Our main interest is to investigate how the manufacturers and the retailer make their own decisions when facing different market power structures in a decentralized supply chain. We aim to determine the amount of production/purchase, advertising expenditure, and inventory level of retailer as well as wholesale/retail prices. The main contribution of this study is to coordinate pricing and advertising in a channel with a dominant retailer and multiple competitive manufacturers. The multi-follower bi-level programming is useful to model and describe this situation.

The contributions of this study are as follows: 
- Investigation of several decisions to improve the performance of the supply chain;

- Allowing each member to make his/her decisions, separately, while being considerate of others' preferences instead of usual optimization approaches;

- Consideration of different market power that makes it possible to influence decisions of the other member.

\section{Problem description}

Decentralization of a supply chain allows members to make decisions, independently. In such a decentralized situation, some channel members may have more power than others to make decisions. These powerful members as leaders can influence or control the decisions of the other members, namely followers. To depict this situation, leader-follower Stackelberg game or bi-level programming is useful.

In this study, a supply chain consisting of multiple competitive manufacturers and one dominant retailer is considered to coordinate the pricing and advertising decisions of all channel members. The manufacturers produce several perishable and substitutable products. It is assumed that each product has two period life cycles. Fresh products can be sold for two periods; therefore, those not sold in the first period can be sold in the next period. The unsold products, whose life cycles are expired, must be thrown away. The retailer orders only refresh goods once in each period. Since the consumers prefer fresh goods, the retailer suggests lower prices to encourage consumers to purchase the unsold products to prevent their quality deterioration. Some of these products are substitutable. It means that if a product is not available when it is demanded, its substitute will be offered instead. Therefore, an increase in the price of each product leads to an increase in the demand of its substitute.

It is possible to inform and persuade consumers by expending more costs for advertising, which can lead to higher profit through more sales. The goal of advertising is to increase the demand of the final consumers. Both pricing and advertising may be applied as marketing tools to attract customers and increase demand. Advertising plays an important role in stimulating customers. A manufacturer's national advertising is aimed to influence potential consumers to purchase his/her product. On the other hand, a retailer's advertising is intended to increase retail sales.

The aim of each channel member is to determine lot size, prices, and advertising expenditures to maximize its profit or revenue. The considered problem has a hierarchical decision-making structure; therefore, compared to the single-level model, the Bi-
Level Programming Problem (BLPP) must be used to facilitate the formulation of the problem. In addition, bi-level programming is useful for consecutive decisionmaking. Because it is assumed that the retailer plays a more dominant role than the manufacturers do, the retailer is considered as the upper-level leader and the manufacturers are considered as the lower-level followers.

This structure may be used in some distribution channels of perishable products, such as the channel of vegetables, dairy, and other foods.

This problem is formulated as a bi-level programming model to allow both retailer and manufacturers to decide independently, according to each other's decisions. Hence, each member of the channel tries to maximize his/her profit.

The general bi-level programming models are as follows:

$$
\min _{x \in X, y} F(x, y)
$$

s.t.:

$$
\begin{aligned}
& G(x, y) \leq 0, \\
& \min _{y} f(x, y),
\end{aligned}
$$

s.t.:

$$
g(x, y) \leq 0
$$

where $x \in \mathbb{R}^{n_{1}}$ and $y \in \mathbb{R}^{n_{2}}$. Upper-level (leader) constraints consist of variables from both levels (in contrast with the constraints specified by set $\mathrm{X}$ ) and play a very particular role, indirectly as they do not enforce the lower-level (follower) decision-making [23].

\subsection{Assumptions and notations}

Some of the other assumptions considered to construct the model are as follows:

1. Life cycles of all products are considered to be the same and equal to two periods;

2. It is assumed that planning horizon is equal to the products' life cycle;

3. The retailer's demand of each product is equal to the final consumers' order for this product;

4. Demand of each product is price sensitive (a function of its price, price of substitutable products, and competitive prices as well as advertising expenditure);

5. The retailer purchases only fresh products from the manufacturers;

6. The retail prices of each fresh product and unsold product are different;

7. No shortage is permitted; 
8. The inventory of each product in the retailer stage is considered;

9. The manufacturers have a finite supply capacity, i.e., capacity constraint;

10. Retailer has a limited warehousing space;

11. Each stage has a limited budget.

The following parameters are common for both the manufacturer and retailer:

$j \quad$ Index of periods;

$i \quad$ Index of products;

$k \quad$ Index of manufacturers;

$N \quad$ Number of products;

$K \quad$ Number of manufacturers;

$J_{i} \quad$ Set of products that can be substituted by product $i$.

The parameters and variables for the retailer (leader) are presented in the following:

$\alpha_{i k}^{j} \quad$ A constant in the product $i$ 's demand function of the retailer from manufacturer $k$ in the period $j$ which represents its market scale;

$\beta_{i l k}^{j} \quad$ Coefficient of the demand elasticity between products $i$ and $l$ for manufacturer $k$ of the retailer in the period $j$;

$d_{i k}^{j} \quad$ Demand of product $i$ produced by manufacturer $k$ in the period $j$ from final consumers;

$h_{i} \quad$ Retailer's holding cost per unit of product $i$ 's inventory per unit of time;

$O_{i k} \quad$ Logistic cost for retailer per order of product $i$ from manufacturer $k$;

$l_{i k} \quad$ Required space to store a unit of product $i$ purchased from manufacturer $k$;

F Retailer's fixed costs for the facilities to carry;

$M \quad$ Available warehouse space for retailer;

$B R \quad$ Available budget of retailer;

$a_{i k} \quad$ Decision variable, the retailer's local advertising expenditure of product $i$ for manufacturer $k$;

$p_{i k}^{j} \quad$ Decision variable, retail price of product $i$ purchased from manufacturer $k$ charged to the customer in the period $j$;

$q_{i k}^{j} \quad$ Decision variable, retailer's order quantity of product $i$ in the period $j$ from manufacturer $k$;
$I_{i k}^{j} \quad$ Decision variable, retailer's inventory level of product $i$ purchased from manufacturer $k$ in the period $j$.

Parameters and variables of the manufacturers (followers) are as follows:

$P_{i k} \quad$ Production capacity of product $i$ for manufacturer $k$;

$C_{i k} \quad$ Production cost per unit of product $i$ for manufacturer $k$;

$g_{k} \quad$ Fixed costs of the facilities to manufacture the products for manufacturer $k$;

$B M_{k} \quad$ Available budget of manufacturer $k$;

$t_{i k} \quad$ Decision variable, the manufacturer $k$ 's participation rate of product $i$;

$A_{i k}^{\prime} \quad$ Decision variable, the manufacturer $k$ 's national advertising expenditure of product $i$;

$w_{i k} \quad$ Decision variable, wholesale price of product $i$ charged to retailer by manufacturer $k$;

$Q_{i k}^{j} \quad$ Decision variable, production quantity of product $i$ in the $j$ th period by manufacturer $k$.

\subsection{Mathematical model}

A channel composed of multiple manufacturers and one dominant retailer is considered in which the manufacturers produce several substitutable and perishable products. The demand of each retailer $d_{i k}^{j}\left(p_{i k}^{j}, a_{i k}, A_{i k}^{\prime}\right)$ is a function of retail prices, $p_{i k}^{j}$, and advertising expenditures, $a_{i k}$ and $A_{i k}^{\prime}$. Hence, the demand functions are as follows [17]:

$$
\begin{aligned}
& d_{i k}^{j}\left(p_{i k}^{j}, a_{i k}, A_{i k}^{\prime}\right)=u_{i k}^{j}\left(p_{i k}^{j}\right) \cdot K\left(a_{i k}, A_{i k}^{\prime}\right) \\
& \forall i, i=1,2, \cdots, N ; \quad \forall j, j=1,2 ; \\
& \forall k, k=1,2, \cdots, K,
\end{aligned}
$$

where $u_{i k}^{j}\left(p_{i k}^{j}\right)$ shows the impact of the retail price on the retailer's demand, and $K\left(a_{i k}, A_{i k}^{\prime}\right)$ demonstrates the impact of the advertising expenditures on the demand, also known as the sale response function.

A linear function is assumed for $u_{i k}^{j}\left(p_{i k}^{j}\right)$ as follows:

$$
\begin{aligned}
& u_{i k}^{j}\left(p_{i k}^{j}\right)=\alpha_{i k}^{j}-\beta_{i i k}^{j} p_{i k}^{j}+\sum_{l \in J_{i}} \beta_{i l k}^{j} p_{l k}^{j}+\sum_{f \neq k} \beta_{i l f}^{j} p_{l f}^{j} \\
& \forall i, i=1,2, \cdots, N ; \quad \forall j, j=1,2 \\
& \forall k, k=1,2, \cdots, K .
\end{aligned}
$$

The substitutability of products is shown by $\sum_{l \in J_{i}}$ 
$\beta_{i l k}^{j} p_{l k}^{j}$ in Eq. (2). To put it differently, if the price of each product increases, then the demand of its substitute increases. The impact of competition between manufacturers is shown through $\sum_{f \neq k} \beta_{i l f}^{j} p_{l f}^{j}$, which means that increasing its competitors' prices leads to an increase in demand [24].

There are several estimations of the sales response function with respect to the advertising expenditures in the literature. Since both types of advertising efforts could influence sales, the advertising effects on the consumer demand are considered as follows:

$$
K\left(a_{i k}, A_{i k}^{\prime}\right)=k_{r}^{i k} \sqrt{a_{i k}}+k_{m}^{i k} \sqrt{A_{i k}^{\prime}}
$$

where $k_{r}^{i k}$ and $k_{m}^{i k}$ are positive constants indicating the efficiency of each type of advertising in attracting demand. The demand in Eq. (5) is an increasing and concave function with respect to $a_{i k}$ and $A_{i k}^{\prime}$ because of "advertising saturation effect". It means that spending additional advertising expenditure continuously weakens the demand [17].

Lemma. $K\left(a_{i k}, A_{i k}^{\prime}\right)$ is concave in $A_{i k}^{\prime}$.

Proof. The concave property of $K\left(a_{i k}, A_{i k}^{\prime}\right)$ can be verified by taking the second-order derivative of Eq. (7) with respect to $A_{i k}^{\prime}$ :

$$
\partial^{2} K\left(a_{i k}, A_{i k}^{\prime}\right) / \partial A_{i k}^{\prime 2}=-0.25 k_{m}^{i k} A_{i k}^{\prime-3 / 2} .
$$

Since $k_{m}^{i k}, A_{i k}^{\prime}>0$, Eq. (6) is strictly negative. Therefore, $K\left(a_{i k}, A_{i k}^{\prime}\right)$ is concave in $A_{i k}^{\prime}$.

It can be proved that $K\left(a_{i k}, A_{i k}^{\prime}\right)$ is concave in $a_{i k}$, similarly. Since $K\left(a_{i k}, A_{i k}^{\prime}\right)$ is concave in both of its variables, it is a concave function.

Given the above, demand functions can be shown as follows:

$$
\begin{aligned}
& d_{i k}^{j}\left(p_{i k}^{j}, a_{i k}, A_{i k}^{\prime}\right)=\left(\alpha_{i k}^{j}-\beta_{i i k}^{j} p_{i k}^{j}+\sum_{l \in J_{i}} \beta_{i l k}^{j} p_{l k}^{j}\right. \\
& \left.\quad+\sum_{f \neq k} \beta_{i l f}^{j} p_{l f}^{j}\right) \cdot\left(k_{r}^{i k} \sqrt{a_{i k}}+k_{m}^{i k} \sqrt{A_{i k}^{\prime}}\right) \\
& \forall i, i=1,2, \cdots, N ; \quad \forall j, j=1,2 ; \\
& \forall k, k=1,2, \cdots, K .
\end{aligned}
$$

The multi-follower bi-level programming model of the problem can be modeled to determine the decision variables of each level, which maximize its own utility:

$$
\max _{p, q, a, I, d} \pi_{r}=\sum_{i=1}^{N} \sum_{j=1}^{2} \sum_{k=1}^{K}\left(p_{i k}^{j}-w_{i k}\right) d_{i k}^{j},
$$

s.t.

$$
\begin{aligned}
& d_{i k}^{j}\left(p_{i k}^{j}, a_{i k}, A_{i k}^{\prime}\right)=\left(\alpha_{i k}^{j}-\beta_{i i k}^{j} p_{i k}^{j}+\sum_{l \in J_{i}} \beta_{i l k}^{j} p_{l k}^{j}\right. \\
& \left.+\sum_{f \neq k} \beta_{i l f}^{j} p_{l f}^{j}\right) \cdot\left(k_{r}^{i k} \sqrt{a_{i k}}+k_{m}^{i k} \sqrt{A_{i k}^{\prime}}\right) \\
& \forall i, i=1,2, \cdots, N ; \quad \forall j, j=1,2 ; \\
& \forall k, k=1,2, \cdots, K, \\
& \sum_{k=1}^{K} \sum_{i=1}^{N}\left(1-t_{i k}\right) a_{i k}+0.5 \sum_{i=1}^{N} \sum_{j=1}^{2} \sum_{k=1}^{K} h_{i} I_{i k}^{j} \\
& +\sum_{i=1}^{N} \sum_{j=1}^{2} \sum_{k=1}^{K} O_{i k} q_{i k}^{j}+F \leq B R,
\end{aligned}
$$

$$
\sum_{i=1}^{N} \sum_{k=1}^{K} l_{i k} I_{i k}^{j} \leq M \quad \forall j, j=1,2
$$

$$
\begin{gathered}
\sum_{i \in J_{i}} q_{i k}^{j} \geq \sum_{i \in J_{i}} d_{i k}^{j}-\sum_{i \in J_{i}} I_{i k}^{j-1} \quad \forall i, i=1,2, \cdots, N ; \\
\forall j, j=1,2 ; \quad \forall k, k=1,2, \cdots, K,
\end{gathered}
$$

$\sum_{i \in J_{i}} I_{i k}^{j}=\sum_{i \in J_{i}} q_{i k}^{j}-\sum_{i \in J_{i}} d_{i k}^{j} \quad \forall i, i=1,2, \cdots, N$

$$
\forall j, j=1,2 ; \quad \forall k, k=1,2, \cdots, K,
$$

$$
\begin{gathered}
p_{i k}^{j}, I_{i k}^{j}, d_{i k}^{j}, q_{i k}^{j}, a_{i k} \geq 0 \quad \forall i, i=1,2, \cdots, N ; \\
\forall j, j=1,2 ; \quad \forall k, k=1,2, \cdots, K,
\end{gathered}
$$

$$
\max _{w, Q, A, D} \pi_{m}=\sum_{i=1}^{N} \sum_{j=1}^{2} w_{i k} Q_{i k}^{j}-\sum_{i=1}^{N} t_{i k} a_{i k}
$$$$
-\sum_{i=1}^{N} A_{i k}^{\prime}-\sum_{i=1}^{N} \sum_{j=1}^{2} C_{i k} Q_{i k}^{j}-g_{k}
$$

$\forall k, k=1,2, \cdots, K$,

s.t.:

$$
\begin{array}{ll}
\sum_{i=1}^{N} t_{i k} a_{i k}+\sum_{i=1}^{N} A_{i k}^{\prime}+\sum_{i=1}^{N} \sum_{j=1}^{2} C_{i k} Q_{i k}^{j}+g_{k} \leq B M_{k} \\
Q_{i k}^{j} \leq P_{i k} & \forall i, i=1,2, \cdots, N ; \\
\forall j, j=1,2, & \forall i, i=1,2, \cdots, N \\
\sum_{i \in J_{i}} Q_{i k}^{j} \geq \sum_{i \in J_{i}} d_{i k}^{j} &
\end{array}
$$




$$
\begin{aligned}
& \forall j, j=1,2, \\
& w_{i k}, Q_{i k}^{j}, A_{i k}^{\prime} \geq 0 \quad 0 \leq t_{i k} \leq 1, \\
& \forall i, i=1,2, \cdots, N ; \quad \forall j, j=1,2 .
\end{aligned}
$$

Objective function (10) maximizes the net revenue of the retailer in planning horizon from sales. Constraint set (11) shows the dominant retailer's demand for each product in each period which is a function of its retail price, the retail prices of the substitutable products, and the retail prices of the other competitors as well as advertising expenditures. Constraint sets (12) and (13) demonstrate the limited budget and warehouse in each period for retailer, respectively. Constraint set (14) does not allow the shortage. Constraint set (15) demonstrates the amount of retailer's inventory in each period. Constraint set (16) shows the allowed sign of the retailer's decision variables. Objective function (17) maximizes the net profit of each manufacturer in the planning horizon. The profit of the manufacturer equals the revenue gained by sales minus the costs including advertising, production, and fixed costs. Constraint (18) shows the limited budget in each period. Constraint set (19) demonstrates the limited production capacity in each period. Constraint set (20) prevents the lack. Constraint set (21) shows the allowed sign of the manufacturer's decision variables.

The first inventory level of each product for retailer is assumed to be zero, i.e., $I_{i k}^{0}=0, \forall i, i=$ $1,2, \cdots, N ; \forall k, k=1,2, \cdots, K$.

\section{The proposed algorithm}

It is proved that the proposed bi-level programming model is NP-hard (see Appendix A). Therefore, metaheuristic methods are useful to solve it. Hence, simulated annealing is used to solve the proposed model. $\mathrm{SA}$ as a form of local search algorithm (a descent algorithm) commences from an initial solution. The basis of SA is the rules of statistical mechanics so that the annealing process comprises warming and, then, slowly cooling a material to obtain a strong crystalline structure. The strength of the achieved structure depends upon the metals' cooling rate. Low initial temperature or fast cooling disrupts the process by not reaching the thermal equilibrium at each temperature. The SA algorithm simulates the energy changes in a system that is exposed to a cooling process until it converges to an equilibrium state. This mechanism can be applied to an optimization problem. The objective function of the problem plays the role of the system energy state. A solution to the optimization problem is a system state. The decision variables of the problem are similar to the molecular positions [25].

The important parameters of SA include an initial value of temperature, a cooling function, the number of
Table 1. The notations of the algorithm parameters.

\begin{tabular}{lc}
\hline \multicolumn{1}{c}{ Parameters } & Notation \\
\hline Starting temperature & $T_{\max }$ \\
Final temperature & $T_{\min }$ \\
Number of iteration & $f$ \\
at each temperature & \\
Number of neighbors & $n s$ \\
$\begin{array}{l}\text { Number of temperature levels } \\
\text { between } T_{\max } \text { and } T_{\min }\end{array}$ & $q l$ \\
\hline
\end{tabular}

neighbors to be searched at each temperature (to reach equilibrium state), and a stopping criterion that are used terminate the algorithm [26]. The linear cooling as a cooling function and the termination condition reaching the final temperature are considered in this study. Neighbors are generated through migration mechanism. In this mechanism, a neighbor is generated from the current solution by relocating two randomly selected positions into two new randomly selected positions. Table 1 shows the notations of the algorithm parameters.

Figure 1 demonstrates the details of SA algorithm applied to the proposed algorithm.

\subsection{Parameter tuning}

Determining the appropriate values for the parameters of algorithm can affect the quality of the solutions and run time. ANOVA is one of the most common approaches in the design of experiments. This approach identifies the parameters with significant effect on the response function. The sum of objective functions of all channel members is considered as a response function. Initial implementations of test problems demonstrate that the change in the values of $T_{\max }, T_{\min }$, and $q l$ cannot improve the value of response function. Hence, the values of these parameters can be fixed at first as follows:

$$
T_{\max }=70 ; \quad q l=10 ; \quad T_{\min }=20 .
$$

A general factorial Design Of Experiment (DOE) is considered to investigate the effect of the parameters. From the initial experimentation, two factors must be studied. In addition, for each factor, two levels should be examined. The values of these levels are observed in Table 2.

For each combination of two factors under study,

Table 2. Levels of DOE.

\begin{tabular}{cccc}
\hline Parameters & Label & \multicolumn{2}{c}{ Levels } \\
\hline$f$ & $\mathrm{~A}$ & 20 & 30 \\
$n s$ & $\mathrm{~B}$ & 20 & 30 \\
\hline
\end{tabular}




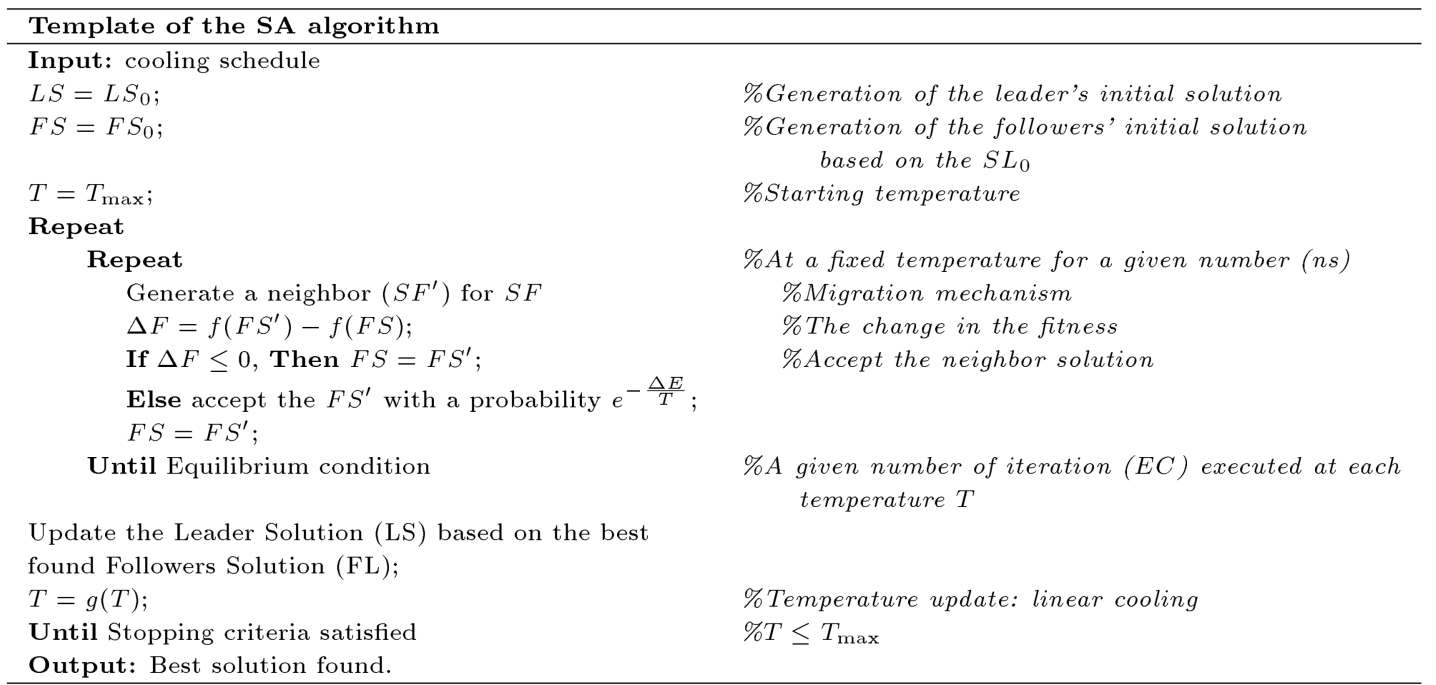

Figure 1. Details of the SA.

Table 3. Dataset of problem parameters.

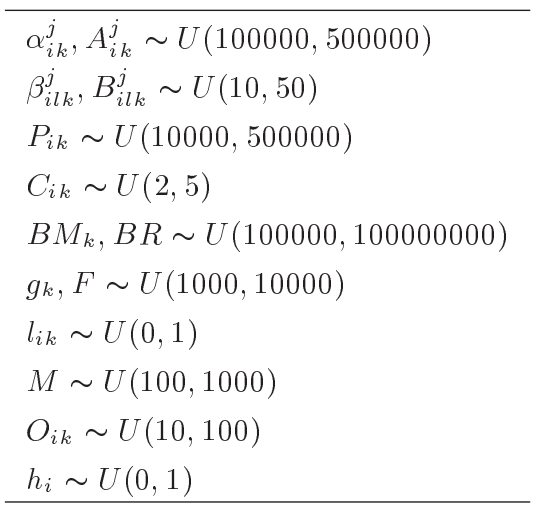

45 problems randomly generated are solved to measure the responses. These problems are selected from a given dataset, as shown in Table 3 .

Table 4 demonstrates the analysis of variance (ANOVA) while the response is the value of the fitness function

The first column in Table 4 named "sources" denotes the factors (parameters) which influence the response function (the value of the fitness function). The second column indicates the degrees of freedom for each factor. The third column points to the sum of squares. The fourth column identified as "MS" reveals the deviations from the sample mean. The results of
F-test are presented in $\mathrm{F}$ column. The last column indicates the significance level. According to Table 4, the interaction between parameters has significant effect at the 0.1 level. Student-Newman-Keules test is used to choose the best level for the significant parameters after implementing experiment [27]. The results of parameter tuning are as follows:

$$
n s=20, \quad f=30 .
$$

\subsection{Performance measurement}

To measure the quality of solutions obtained by the applied algorithm (SA), its results are compared with those by the proposed PSO by Gao et al. [28]. As a comparison criterion, Relative Percentage Deviation (RPD) is beneficial, which is calculated as follows:

$$
\mathrm{RPD}=\frac{\text { Sol }_{\text {best }}-\text { Sol }_{\text {alg }}}{\text { Sol }_{\text {best }}} \times 100,
$$

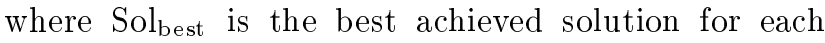
instance through each of two algorithms, and Sol alg is the best solution found by the applied SA. Solving has been implemented on a personal computer with Intel (R) core $^{\mathrm{TM}}$ i3 CPU $2.4 \mathrm{GHz}$ and $2 \mathrm{~GB}$ RAM, and the proposed algorithms have been coded with MATLAB 2013.

The results of this comparison are presented in Table 5 .

Table 4. ANOVA table.

\begin{tabular}{lccccc}
\hline Sources & $\boldsymbol{d} \boldsymbol{f}$ & SS & MS & F & $\boldsymbol{P}$-value \\
\hline $\mathrm{A}$ & 1 & $9.02 \mathrm{E}+18$ & $9.02 \mathrm{E}+18$ & 0.00034 & 0.9853 \\
$\mathrm{~B}$ & 1 & $2.05 \mathrm{E}+18$ & $2.05 \mathrm{E}+18$ & 0.00007 & 0.9933 \\
$\mathrm{~A} \times \mathrm{B}$ & 1 & $8.55 \mathrm{E}+22$ & $8.55 \mathrm{E}+22$ & 3.18814 & 0.0759 \\
Error & 176 & $4.72 \mathrm{E}+24$ & $2.68 \mathrm{E}+22$ & & \\
Total & 179 & $4.81 \mathrm{E}+24$ & & & \\
\hline
\end{tabular}


Table 5. Results of performance measurement.

\begin{tabular}{ccc}
\hline $\begin{array}{c}\text { Problem size } \\
(\boldsymbol{N}, \boldsymbol{K})\end{array}$ & $\begin{array}{c}\text { Average } \\
\text { of RPD }\end{array}$ & $\begin{array}{c}\text { Average of } \\
\text { SA run time } \\
\text { (second) }\end{array}$ \\
\hline Small $(10,5)$ & $2.05 \%$ & 120 \\
Medium $(50,10)$ & $1.88 \%$ & 540 \\
Large $(70,15)$ & $1.24 \%$ & 1100 \\
\hline
\end{tabular}

According to Table 5, the greater problem size will lead to the larger deviation and more run time due to larger feasible space, which should be searched. It is interpreted from these results that the applied algorithm is $2.05 \%$ below the best obtained solution on average in the small size, $1.88 \%$ in the medium size, and $1.24 \%$ in the large size.

\section{Numerical example}

The members' decisions are influenced by the consumers' demand. The demand is affected by the market scale and elasticity coefficient parameters. Therefore, the impact of these parameters on the members' decisions is examined.

To analyze the effect of retail/wholesale prices on the chain decisions, a small example with 10 products and 5 retailers is examined. These effects are related to the market scale and elasticity coefficient parameters. To investigate the effect of these parameters, the values of each of them vary, while other parameters are constant. The results of changing $\alpha_{i k}^{j}$ are presented in Table 6. It is assumed that all $\alpha_{i k}^{j}$ s are equal.

Table 6 indicates that a larger dominant retailer's market scale results in lower retail prices to invite consumers for more purchase. Furthermore, the manufacturers should decrease the wholesale prices to encourage the dominant retailer to buy. They may incur more cost for advertising. Therefore, both the dominant retailer and the manufacturers can gain more profit through more sales. The results demonstrate that when market scale of dominant retailer is enlarged, the manufacturers and dominant retailer gain more profit through more sales. Increased sales are achieved by more advertising and lower prices to attract consumers.

Table 7 shows the results of the coefficient of the retailer's demand elasticity. It is assumed that all $\beta_{i l k}^{j} \mathrm{~s}$ are equal.

According to Table 7 , if consumers are sensitive to the retail prices, the dominant retailer should lessen the proposed prices to maintain and increase his/her customers. In such a competitive environment, the manufacturers may decrease their wholesale prices or increase their national advertising expenditure to improve their sale amount. In this case, the dominant retailer and the manufacturers may deal with profit reduction. In other words, when the consumers are sensitive to the prices, the manufacturers and dominant retailer must offer their products with lower prices, which can encourage the costumers or more expenditure for advertising to inform them about more purchase. These efforts lead to an increase in their profit.

\section{Conclusion}

Decentralization is the main purpose of this study. One aspect in the decentralized channels was the difference between power of members to make decisions and controlling the decisions of the other members. Bilevel programming is a helpful approach to confronting these situations.

This study considered a two-stage supply chain consisting of one dominant retailer and multiple competitive manufactures which produce several perishable and substitutable products. The aim of this study was investigation of coordination of pricing and cooperative advertising in a decentralized supply chain. In this decentralized chain, the dominant retailer has more power to control other members' decisions. Hence, the former plays the leader role, and the manufacturers are his/her followers. Each member decides on the prices, advertising expenditures, as well as production or purchase amount. This problem was modeled as a multi-follower bi-level programming model.

Since it is proved that the proposed bi-level programming model is NP-hard, metaheuristic methods are useful to solve it. Hence, simulated annealing was applied to solve the proposed model. Then, this algorithm was compared with an existing PSO method. The implementation of test problems indicated an acceptable preference of SA to the PSO in this problem.

The illustrated results from the proposed model demonstrated that when the dominant retailer was price-sensitive, the manufacturers should decrease the wholesale prices and increase the national advertising expenditures to encourage the retailer to purchase. This causes an increase in their profits through enlarged sales. On the other side, the dominant retailer could increase the profit through fixed retail prices and increase sales due to more advertising. However, when the consumers were price-sensitive, both the dominant retailer and manufacturers should reduce their prices to decrease profit reduction.

The examination of market scales demonstrated that when the market scale of the manufacturers or the dominant retailer is enlarged, both of channel members should decrease their prices to increase their market share and their profit.

Our analysis might also have some limitations. Firstly, we investigated a retailer with vertical dominance, while parallel dominance is possible in the 
Table 6. The effects of changing $\alpha_{i k}^{j}$.

\begin{tabular}{|c|c|c|c|c|c|c|c|}
\hline \multirow{2}{*}{ Problem } & \multirow{2}{*}{ Result } & \multirow{2}{*}{$\begin{array}{c}\text { Period } \\
(j)\end{array}$} & \multicolumn{5}{|c|}{$k$} \\
\hline & & & $k=1$ & $k=2$ & $k=3$ & $k=4$ & $k=5$ \\
\hline \multirow{12}{*}{ 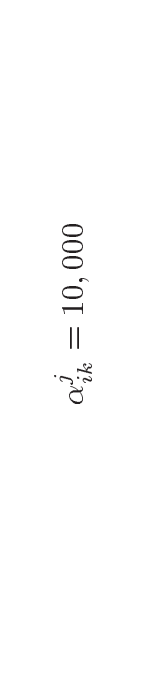 } & \multirow{2}{*}{$\bar{p}_{i k}^{j}$} & $j=1$ & 13,637 & 15,086 & 16,025 & 16,985 & 13,134 \\
\hline & & $j=2$ & 10,278 & 12,812 & 15,046 & 13,275 & 10,130 \\
\hline & $\bar{w}_{i k}$ & $j=1,2$ & 9,863 & 9,071 & 10,723 & 11,909 & 8,984 \\
\hline & \multirow{2}{*}{$\bar{q}_{i k}^{j}$} & $j=1$ & 10,401 & 41,505 & 12,469 & 69,436 & 87,465 \\
\hline & & $j=2$ & 9,533 & 29,830 & 57,348 & 47,806 & 45,112 \\
\hline & \multirow{2}{*}{$\bar{Q}_{i k}^{j}$} & $j=1$ & 20,401 & 41,505 & 12,469 & 69,436 & 87,465 \\
\hline & & $j=2$ & 30,533 & 39,830 & 57,348 & 47,806 & 45,112 \\
\hline & $\bar{a}_{i k}$ & $j=1,2$ & 95,461 & 151,383 & 128,082 & 202,976 & 275,910 \\
\hline & $\bar{A}_{i k}^{\prime}$ & $j=1,2$ & 108,603 & 126,417 & 104,275 & 98,355 & 112,451 \\
\hline & $\bar{t}_{i k}$ & $j=1,2$ & 0.390 & 0.318 & 0.139 & 0.403 & 0.517 \\
\hline & \multirow{2}{*}{\multicolumn{2}{|c|}{$\begin{array}{c}\text { Retailer's revenue } \\
\text { Manufacturer's } \\
\text { profit }\end{array}$}} & & & $4,493,202,552$ & & \\
\hline & & & $221,689,379$ & $1,584,907,686$ & $4,027,825,510$ & $868,913,621$ & $1,902,744,442$ \\
\hline \multirow{12}{*}{$\begin{array}{l}8 \\
8 \\
20 \\
\sim \\
\| 1 \\
\sigma \\
\sigma\end{array}$} & \multirow{2}{*}{$\bar{p}_{i k}^{j}$} & $j=1$ & 12,453 & 14,698 & 15,907 & 16,100 & 10,238 \\
\hline & & $j=2$ & 9,497 & 10,082 & 12,043 & 13,022 & 10,003 \\
\hline & $\bar{w}_{i k}$ & $j=1,2$ & 6,396 & 4,948 & 5,381 & 6,857 & 12,891 \\
\hline & \multirow{2}{*}{$\bar{q}_{i k}^{j}$} & $j=1$ & 17,580 & 68,910 & 19,252 & 115,661 & 89,297 \\
\hline & & $j=2$ & 19,829 & 35,250 & 81,106 & 130,943 & 49,135 \\
\hline & \multirow{2}{*}{$\bar{Q}_{i k}^{j}$} & $j=1$ & 17,580 & 68,910 & 19,252 & 115,661 & 89,297 \\
\hline & & $j=2$ & 19,829 & 35,250 & 81,106 & 130,943 & 49,135 \\
\hline & $\bar{a}_{i k}$ & $j=1,2$ & 47,825 & 306,576 & 602,156 & 207,863 & 8,381 \\
\hline & $\bar{A}_{i k}^{\prime}$ & $j=1,2$ & 109,899 & 136,769 & 164,632 & 107,005 & 218,545 \\
\hline & $\bar{t}_{i k}$ & $j=1,2$ & 0.624 & 0.660 & 0.587 & 0.498 & 0.561 \\
\hline & \multicolumn{2}{|c|}{ Retailer's revenue } & & & $4,649,741,816$ & & \\
\hline & \multicolumn{2}{|c|}{$\begin{array}{c}\text { Manufacturer's } \\
\text { profit }\end{array}$} & $228,107,853$ & $1,907,899,586$ & $5,911,247,655$ & $3,804,674,050$ & $4,855,242,348$ \\
\hline \multirow{12}{*}{$\begin{array}{c}8 \\
8 \\
0 \\
10 \\
11 \\
0+\infty\end{array}$} & \multirow{2}{*}{$\bar{p}_{i k}^{j}$} & $j=1$ & 11,152 & 12,907 & 14,807 & 16,010 & 9,856 \\
\hline & & $j=2$ & 8,902 & 9,108 & 11,652 & 12,905 & 8,913 \\
\hline & $\bar{w}_{i k}$ & $j=1,2$ & 5,111 & 2,898 & 4,758 & 5,470 & 8,950 \\
\hline & \multirow{2}{*}{$\bar{q}_{i k}^{j}$} & $j=1$ & 82,723 & 69,982 & 25,257 & 210,032 & 95,074 \\
\hline & & $j=2$ & 21,488 & 44,637 & 89,932 & 176,688 & 51,364 \\
\hline & \multirow{2}{*}{$\bar{Q}_{i k}^{j}$} & $j=1$ & 82,723 & 69,982 & 25,257 & 210,032 & 95,074 \\
\hline & & $j=2$ & 21,488 & 44,637 & 89,932 & 176,688 & 51,364 \\
\hline & $\bar{a}_{i k}$ & $j=1,2$ & $1,229,306$ & 39,797 & 79,248 & 258,065 & 41,384 \\
\hline & $\bar{A}_{i k}^{\prime}$ & $j=1,2$ & 119,060 & 140,112 & 172,981 & 116,125 & 220,105 \\
\hline & $\bar{t}_{i k}$ & $j=1,2$ & 0.634 & 0.775 & 0.753 & 0.594 & 0.889 \\
\hline & \multicolumn{2}{|c|}{ Retailer's revenue } & & & $5,815,400,937$ & & \\
\hline & \multicolumn{2}{|c|}{$\begin{array}{c}\text { Manufacturer's } \\
\text { profit }\end{array}$} & $2,121,310,632$ & $2,861,836,770$ & $6,453,043,706$ & $5,982,075,344$ & $6,131,049,799$ \\
\hline
\end{tabular}


Table 7. The effects of changing $\beta_{i l k}^{j}$.

\begin{tabular}{|c|c|c|c|c|c|c|c|}
\hline \multirow{2}{*}{ Problem } & \multirow{2}{*}{ Result } & \multirow{2}{*}{$\begin{array}{c}\text { Period } \\
\quad(j)\end{array}$} & \multicolumn{5}{|c|}{$k$} \\
\hline & & & $k=1$ & $k=2$ & $k=3$ & $k=4$ & $k=5$ \\
\hline \multirow{12}{*}{ 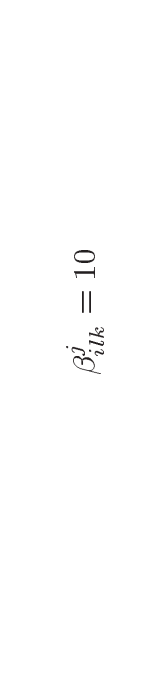 } & \multirow{2}{*}{$\bar{p}_{i k}^{j}$} & $j=1$ & 11,246 & 13,468 & 14,809 & 14,958 & 12,795 \\
\hline & & $j=2$ & 8,693 & 11,005 & 10,586 & 13,760 & 9,961 \\
\hline & $\bar{w}_{i k}$ & $j=1,2$ & 2,834 & 2,974 & 3,879 & 6,364 & 14,513 \\
\hline & \multirow{2}{*}{$\bar{q}_{i k}^{j}$} & $j=1$ & 129,801 & 62,794 & 264,530 & 88,463 & 53,752 \\
\hline & & $j=2$ & 223,626 & 34,077 & 272,722 & 63,625 & 85,194 \\
\hline & \multirow{2}{*}{$\bar{Q}_{i k}^{j}$} & $j=1$ & 129,801 & 62,794 & 264,530 & 88,463 & 53,752 \\
\hline & & $j=2$ & 223,626 & 34,077 & 272,722 & 63,625 & 85,194 \\
\hline & $\bar{a}_{i k}$ & $j=1,2$ & $5,308,966$ & 255,855 & $34,815,956$ & 428,051 & $6,470,283$ \\
\hline & $\bar{A}_{i k}^{\prime}$ & $j=1,2$ & 80,100 & 56,316 & 62,725 & 71,489 & 31,618 \\
\hline & $\bar{t}_{i k}$ & $j=1,2$ & 0.478 & 0.524 & 0.405 & 0.498 & 0.430 \\
\hline & \multirow{2}{*}{\multicolumn{2}{|c|}{$\begin{array}{c}\text { Retailer's revenue } \\
\text { Manufacturer's } \\
\text { profit }\end{array}$}} & \multicolumn{5}{|c|}{$46,113,412,890$} \\
\hline & & & $11,876,967,217$ & $2,901,081,837$ & $3,316,707,134$ & $5,919,202,183$ & $6,807,300,341$ \\
\hline \multirow{12}{*}{ 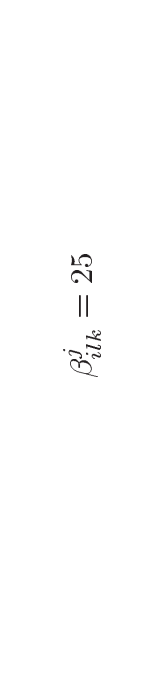 } & \multirow{2}{*}{$\bar{p}_{i k}^{j}$} & $j=1$ & 10,918 & 13,105 & 14,018 & 14,106 & 11,167 \\
\hline & & $j=2$ & 8,101 & 10,907 & 10,006 & 12,987 & 9,605 \\
\hline & $\bar{w}_{i k}$ & $j=1,2$ & 3,636 & 7,084 & 4,009 & 7,488 & 10,722 \\
\hline & \multirow{2}{*}{$\bar{q}_{i k}^{j}$} & $j=1$ & 73,264 & 26,017 & 73,021 & 17,865 & 62,487 \\
\hline & & $j=2$ & 150,451 & 31,035 & 112,988 & 37,691 & 87,555 \\
\hline & \multirow{2}{*}{$\bar{Q}_{i k}^{j}$} & $j=1$ & 73,264 & 26,017 & 73,021 & 17,865 & 62,487 \\
\hline & & $j=2$ & 150,451 & 31,035 & 112,988 & 37,691 & 87,555 \\
\hline & $\bar{a}_{i k}$ & $j=1,2$ & $43,749,515$ & 47,990 & $1,789,220$ & 698,373 & 95,360 \\
\hline & $\bar{A}_{i k}^{\prime}$ & $j=1,2$ & 97,409 & 88,213 & 100,924 & 87,051 & 41,085 \\
\hline & $\bar{t}_{i k}$ & $j=1,2$ & 0.475 & 0.718 & 0.375 & 0.591 & 0.507 \\
\hline & \multirow{2}{*}{\multicolumn{2}{|c|}{$\begin{array}{c}\text { Retailer's revenue } \\
\text { Manufacturer's } \\
\text { profit }\end{array}$}} & \multicolumn{5}{|c|}{$35,944,536,620$} \\
\hline & & & $2,993,244,357$ & $2,397,743,203$ & $1,199,987,822$ & $4,060,456,564$ & $6,198,215,796$ \\
\hline \multirow{12}{*}{ 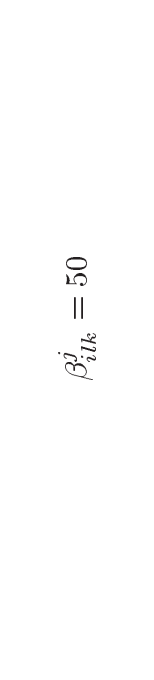 } & \multirow{2}{*}{$\bar{p}_{i k}^{j}$} & $j=1$ & 10,011 & 12,871 & 13,672 & 13,105 & 11,070 \\
\hline & & $j=2$ & 7,106 & 10,050 & 9,921 & 11,905 & 9,053 \\
\hline & $\bar{w}_{i k}$ & $j=1,2$ & 5,550 & 3,505 & 6,597 & 9,911 & 9,778 \\
\hline & \multirow{2}{*}{$\bar{q}_{i k}^{j}$} & $j=1$ & 12,381 & 29,140 & 17,737 & 27,773 & 13,486 \\
\hline & & $j=2$ & 48,603 & 49,578 & 25,250 & 46,456 & 20,022 \\
\hline & \multirow{2}{*}{$\bar{Q}_{i k}^{j}$} & $j=1$ & 12,381 & 29,140 & 17,737 & 27,773 & 13,486 \\
\hline & & $j=2$ & 48,603 & 49,578 & 25,250 & 46,456 & 20,022 \\
\hline & $\bar{a}_{i k}$ & $j=1,2$ & 158,535 & 409,726 & 146,465 & 11,818 & 8,517 \\
\hline & $\bar{A}_{i k}^{\prime}$ & $j=1,2$ & 79,307 & 48,919 & 40,526 & 35,609 & 38,791 \\
\hline & $\bar{t}_{i k}$ & $j=1,2$ & 0.548 & 0.473 & 0.429 & 0.683 & 0.582 \\
\hline & \multirow{2}{*}{\multicolumn{2}{|c|}{$\begin{array}{c}\text { Retailer's revenue } \\
\text { Manufacturer's } \\
\text { profit }\end{array}$}} & & & $8,310,314,262$ & & \\
\hline & & & $2,144,544,362$ & $1,102,833,247$ & $498,727,010$ & $1,298,851,844$ & $3,984,833,136$ \\
\hline
\end{tabular}


channels. Secondly, another decision in a channel, such as supplier selection, routing, etc., can be examined.

\section{References}

1. Hua, Z. and Li, S. "Impacts of demand uncertainty on retailer's dominance and manufacturer-retailer supply chain cooperation", Omega, 36, pp. 697-714 (2008).

2. Fishman, C., The Wal-Mart Effect, New York, Penguin Press (2006).

3. Chutani, A. and Sethi, S.P. "Optimal advertising and pricing in a dynamic durable goods supply chain", Journal of Optimization Theory and Application, 154, pp. 615-643 (2012).

4. Raju, J. and Zhang, Z.J. "Channel coordination in the presence of a dominant retailer", Marketing Science, 24(2), pp. 254-262 (2005).

5. Chen, K.B. and Xiao, T.J. "Demand disruption and coordination of the supply chain with a dominant retailer", European Journal of Operational Research, 197(1), pp. 225-234 (2009).

6. Tsay, A.A. "Risk sensitivity in distribution channel partnership: implications for manufacturer return policies", Journal of Retailing, 78(2), pp. 147-160 (2002).

7. Geylani, T., Dukes, A.J., and Srinivasan, K. "Strategic manufacturer response to a dominant retailer", Marketing Science, 26(2), pp. 164-178 (2007).

8. Lau, A.H.L., Lau, H.S., and Wang, J.C. "How a dominant retailer might design a purchase contract for a newsvendor-type product with price-sensitive demand", European Journal of Operational Research, 190, pp. 443-458 (2008).

9. Pan, K., Lai, K.K., Liang, L., and Leung, S.C.H. "Two-period pricing and ordering policy for the dominant retailer in a two-echelon supply chain with demand uncertainty", Omega, 37, pp. 919-929 (2009).

10. Wang, J.C., Lau, H.S., and Lau, A.H.L. "When should a manufacturer share truthful manufacturing cost information with a dominant retailer?", European Journal of Operational Research, 197, pp. 266-286 (2009).

11. Chen, K. and Zhuang, P. "Disruption management for a dominant retailer with constant demand-stimulating service cost", Computers \& Industrial Engineering, 61, pp. 936-946 (2011).

12. Wang, J.C., Lau, A.H.L., and Lau, H.S. "Dollar vs. percentage markup pricing schemes under a dominant retailer", European Journal of Operational Research, 227, pp. 471-482 (2013).

13. Dukes, A., Geylani, T., and Liu, Y. "Dominant retailers' incentives for product quality in asymmetric distribution channels", Marketing Letters, 25(1), pp. 93-107 (2013).

14. Yue, J., Austin, J., Wang, M.C., and Huang, Z. "Coordination of cooperative advertising in a twolevel supply chain when manufacturer offers discount",
European Journal of Operational Research, 168, pp. 65-85 (2006).

15. Szmerekovsky, J.G. and Zhang, J. "Pricing and twotier advertising with one manufacturer and one retailer", European Journal of Operational Research, 192(3), pp. 904-917 (2009).

16. Xie, J. and Neyret, A. "Co-op advertising and pricing models in manufacturer-retailer supply chains", Computers \& Industrial Engineering, 56, pp.1375-1385 (2009).

17. Xie, J. and Wei, J. "Coordinating advertising and pricing in a manufacturer-retailer channel", European Journal of Operational Research, 197, pp. 785-791 (2009).

18. Yan, R. "Cooperative advertising, pricing strategy and firm performance in the e-marketing age", Journal of the Academy of Marketing Science, 38, pp. 510-519 (2010).

19. Aust, G. and Buscher, U. "Vertical cooperative advertising and pricing decisions in a manufacturer-retailer supply chain: A game-theoretic approach", European Journal of Operational Research, 223, pp. 473-482 (2012).

20. Zhang, J., Gou, Q., Liang, L., and Huang, Z. "Supply chain coordination through cooperative advertising with reference price effect", Omega, 41(2), pp. 345-353 (2013).

21. Mokhlesian, M. and Zegordi, S.H. "Application of multidivisional bi-level programming to coordinate pricing and inventory decisions in a multiproduct competitive supply chain", Int. J. Adv. Manuf. Technol., 71, pp. 1975-1989 (2014).

22. Chintapalli, P. "Simultaneous pricing and inventory management of deteriorating perishable products", Annals of Operations Research, 229(1), pp. 287301(2015).

23. Colson, B., Marcotte, P., and Savard, G. "Bilevel programming: A survey", 4OR, 3, pp. 87-107 (2005).

24. Ingene, C.A. and Parry, M.E. "Bilateral monopoly, identical distributors, and game-theoretic analyses of distribution channels", Journal of the Academy of Marketing Science, 35, pp. 586-602 (2007).

25. Talbi, E.G., Metaheuristics: From Design to Implementation, New Jersey: John Wiley \& Sons, Inc., Hoboken (2009).

26. Koulamas, C., Antony, S.R., and Jaen, R. "A survey of simulated annealing applications to operations research problems", Omega, 22(1), pp. 41-56 (1994).

27. Hicks, C.R., Fundamental Concepts in the Design of Experiments, Fourth Ed., New York, Oxford University Press (1993).

28. Gao, Y., Zhang, G., Lu, J., and Wee, H.M. "Particle swarm optimization for bi-level pricing problems in supply chains", Journal of Global Optimization, 51, pp. 245-254 (2011).

29. Sahni, S. "Computationally related problems", SIAM Journal on Computing, 3, pp. 262-279 (1974). 


\section{Appendix A}

If a known NP-hard problem can be reduced to a problem through a polynomial-time transformation, it is proved that the problem is NP-hard. Hence, to show the complexity of the proposed problem, consider the following nonconvex Quadratic Programming (QP) model:

$$
-\min \quad-F(X)=\frac{1}{2} X Q X^{T}+d X^{T} \equiv \max F(X),
$$

s.t.:

$$
A X \leq b
$$

Suppose that $X=\left(x_{1}, x_{2}, x_{3}, x_{4}, x_{5}\right), d=(0, C$, $1,1,0)$,

$$
\begin{aligned}
A & =\left[\begin{array}{ccccc}
0 & C & 1 & 1 & 0 \\
0 & 1 & 0 & 0 & 0 \\
0 & -1 & 0 & 0 & 0 \\
-1 & -1 & -1 & -1 & -1
\end{array}\right], \quad b=\left[\begin{array}{c}
B M-g \\
P \\
0 \\
0
\end{array}\right] \\
Q & =\left[\begin{array}{ccccc}
0 & -1 & 0 & 0 & 0 \\
-1 & 0 & 0 & 0 & 0 \\
0 & 0 & 0 & 0 & 0 \\
0 & 0 & 0 & 0 & 0 \\
0 & 0 & 0 & 0 & 0
\end{array}\right]
\end{aligned}
$$

According to the above definitions, the mentioned QP can be rewritten as follows:

$$
\max \quad x_{1} x_{2}-x_{3}-x_{4}-C x_{2},
$$

s.t.:

$$
\begin{aligned}
& x_{3}+x_{4}+C x_{2} \leq B M_{k}-g_{k}, \\
& x_{2} \leq P_{i k}, \\
& x_{5}-x_{2} \leq 0 \\
& x_{1}, x_{2}, x_{3}, x_{4}, x_{5} \geq 0 .
\end{aligned}
$$

Since $Q$ is not PSD, it is interpreted that the above nonconvex quadratic programming problem is NPHard [29].

Through below transformations, the above QP is transformed to the lower-level (manufacturer) problem:

$$
\begin{gathered}
x_{1}=w_{i k} \quad i=1,2, \cdots, N ; \\
k=1,2, \cdots, K, \\
x_{2}=Q_{i k}^{j} \quad i=1,2, \cdots, N ; \\
k=1,2, \cdots, K ; \quad j=1,2,
\end{gathered}
$$

$$
\begin{gathered}
x_{3}=t_{i k} a_{i k} \quad i=1,2, \cdots, N ; \\
k=1,2, \cdots, K, \quad i=1,2, \cdots, N ; \\
x_{4}=A_{i k}^{\prime} \quad i=1,2, \cdots, N ; \\
k=1,2, \cdots, K, \quad j=1,2, \\
x_{5}=d_{i k}^{j} \quad i=1,2, \cdots, N ; \\
k=1,2, \cdots, K ; \quad i=1,2, \cdots, N ; \\
C=C_{i k} \quad k, \quad k=1,2, \cdots, K \\
k=1,2, \cdots, K \\
P=P_{i k} \\
k=1,2, \cdots, K, \quad k=1,2, \cdots, K . \\
B M=B M_{k} \quad k \\
g=g_{k} \quad k
\end{gathered}
$$

Through these transformations, nonconvex QP is reduced to the manufacturer's problem $(p 1)$ as a subproblem of the proposed problem (main problem). Since this nonconvex quadratic programming problem is NP-hard, the manufacturer's problem is NP-hard, too.

As $(p 1)$ is NP-hard, the main problem is NP-hard, too, because the degree of the complexity of a subproblem is not less than the main problem.

\section{Biographies}

Maryam Mokhlesian received her $\mathrm{PhD}$ degree from Faculty of Industrial \& Systems Engineering at Tarbiat Modares University in 2014. She obtained her MSc and BSc degree from the Department of Industrial Engineering at Amirkabir University of Technology. Her main areas of research are optimization problems, scheduling, supply chain and pricing.

Seyed Hesameddin Zegordi is a Professor of Industrial Engineering in the Faculty of Industrial \& Systems Engineering at Tarbiat Modares University, Iran. He received his $\mathrm{PhD}$ degree from the Department of Industrial Engineering and Management at Tokyo Institute of Technology, Japan in 1994. He holds an MSc degree in Industrial Engineering and Systems from Sharif University of Technology, Iran, and a BSc degree in Industrial Engineering from Isfahan University of Technology, Iran. His main areas of teaching and research interests include production planning and scheduling, multi-objective 
optimization problems, meta-heuristics, quality management, and productivity. He has published several articles in international conferences and academic journals including European Journal of Operational Research, International Journal of Production Re- search, Journal of Operational Research Society of Japan, Computers \& Industrial Engineering, Amirkabir Journal of Science and Engineering, and Scientia Iranica: International Journal of Science and Technology. 